\title{
The laboratory measurement and interpretation of the small strain stiffness of stiff clays
}

\section{A. Gasparre, D.W. Hight, M.R. Coop and R.J. Jardine}

\begin{abstract}
The techniques and procedures currently and recently used to measure and interpret the small strain stiffness of stiff clays in advanced triaxial tests in the UK are reviewed. Differences between reported data sets for the stiffness characteristics of London Clay and the scatter within these data sets appear to be, at least in part, the result of details of specimen preparation, instrument resolution, apparatus configurations for advanced triaxial testing, in particular the connection between the internal load cell and the sample top platen, the ratio of axial strain rate to preceding creep strain rate, and data interpretation, including normalisation.
\end{abstract}

\section{Introduction}

An extensive research study into the behaviour of London Clay at small strains was published by Gasparre et al. (2007), Nishimura et al. (2007) and Hight et al. (2007). This study included advanced triaxial and hollow cylinder tests on London Clay samples retrieved from the excavations for Heathrow Airport's Terminal 5, where the clay is up to 50m thick, comprises lithological units C, B2, A3 and A2 (King, 1981) and is overlain by approximately $6 \mathrm{~m}$ of River Terrace Deposits. This test programme will be referred to herein as IC-T5-07. At small strains the normalised decay curves of undrained stiffness measured in this study were found to differ from normalised decay curves reported previously for the T5 site (Hight et al., 2002), referred to herein as T5-00, which were obtained in commercial tests and which fitted within a previously unpublished database of normalised stiffness variations that had been established using measurements from commercial advanced triaxial tests. This change in the Clay's perceived stiffness characteristics has important practical implications.

The comparison between the new (IC-T5-07) and original (T5-00) data sets is presented in Figure 1 in terms of the decay of secant modulus for undrained triaxial compression, Euv ${ }_{\mathrm{sec}}$, normalised by the estimated mean effective stress in situ, $\mathrm{p}_{\mathrm{o}}$, to which each sample was consolidated prior to shear. Normalised vertical stiffnesses derived from the IC-T5-07 triaxial compression tests are lower than both the T5-00 data and the database at axial strains less than $0.1 \%$ and do not generally show significant degradation of normalised stiffnesses until axial strains exceed $0.01 \%$.

As discussed below, some of the differences evident in Figure 1 may be the result of normalisation and so Figures 2(a) and (b) compare un-normalised undrained secant stiffness data from tests run on samples from similar depths; these two figures highlight the divergence between the two data sets at strains less than 0.02 to $0.1 \%$ and the reasonable agreement at strains greater than $0.1 \%$.

Potential variables that could also explain the differences between the original and new T5 data sets of vertical stiffness, obtained with local displacement measurements on the specimens, are considered herein and comprise: sample quality; sample preparation and setting; stress and strain history, including sampling and reconsolidation stress paths and strains; creep rates prior to shearing; strain rates 
applied during undrained shearing; stress path directions; load cell and other compliances; load cell to sample connections; resolution of instrumentation; accuracy of pressure control; temperature stability; and interpretation of data. To examine the effects of some of these variables, data are drawn from a specially designed set of tests on London Clay samples retrieved from a borehole at a site close to the Queen Mother Reservoir, and so near Terminal 5 in West London. A normalised stiffness decay curve from one of these tests, denoted as QM, is included in Figure 1 and confirms the divergence between the new data and the older commercial data at small strains. The details of all tests reviewed in this paper are set out in Table 1.

The conclusions from the review have implications for the measurement and interpretation of the small strain stiffness of other stiff and hard clays.

\section{Apparatus configurations for advanced triaxial testing}

Advanced triaxial testing is intended here to mean testing which requires the use of a triaxial apparatus typically equipped with an internal load cell, high resolution pressure transducers, high resolution instrumentation for the local measurement of axial and radial strains on the sample (e.g. Jardine et al., 1984; Cuccovillo \& Coop, 1997)), a mid-height pore water pressure probe (e.g. Hight, 1982) and ideally bender elements that measure shear wave velocities in up to three directions (Pennington et al., 1997). Figure 3 shows a sketch of a typical arrangement of a specimen inside an advanced triaxial apparatus carrying two local axial displacement transducers and one radial strain belt. External measurements are also made of the axial displacement, cell pressure and pore pressure at the base of the specimen.

In Figure 3 the axial load is shown being applied centrally to the sample and this requires a connection of some form between the internal load cell and the top platen. The axial load on the sample is increased by pushing the sample against the load cell at an externally controlled constant rate of displacement or at a constant rate of change in axial stress. If the axial load on the sample is to be reduced (e.g. in triaxial extension) this requires a mechanical connection between the load cell and sample.

A primary objective of the advanced triaxial testing discussed herein is the measurement of soil stiffness from strains as low as $0.001 \%$ up to failure, under a range of drained and undrained triaxial stress paths.

\section{Factors affecting the true undrained stiffness characteristics of London Clay}

Before considering the possible effects of the variables in testing procedures and apparatus configurations listed above on the measured stiffness characteristics of London Clay it is helpful to summarise first what has been established regarding the factors which influence its true stiffness characteristics.

\section{Effects of strain level}


Figures 4(a) and (b) show the typical stress-strain behaviour of London Clay over two different strain ranges, observed in an undrained triaxial compression test carried out as part of the IC-T5-07 study on a sample from $6.5 \mathrm{~m}$ below the top of the London Clay at T5. It is characterised by a Kinematic Yield Surface (KYS) within which behaviour is practically linear and straining fully recoverable: see Figure 4(a). The axial strain limit to this linear elastic zone is identified as Y1 in Figure 4(b). Figure 4(c) shows the full tangent and secant modulus decay curves with axial strain, both derived from an average of the two local transducer readings. For stiff clays the size of KYS increases with strain rate (Tatsuoka et al., 1998). Y1 yielding develops at axial strains of 0.001 to $0.002 \%$ in London Clay at strain rates up to $0.01 \% / \mathrm{h}$, extending to an axial strain of about $0.008 \%$ at a strain rate of $0.2 \% / \mathrm{h}$. Within the linear elastic zone secant and tangent stiffnesses coincide by definition. Beyond Y1 the tangent stiffness curve degrades faster than the secant curve as plastic strains develop.

\section{Effects of stress level and normalisation}

A key point to emerge from the IC-T5-07 study was that different stiffness-mean effective stress relationships apply to (i) intact specimens tested at initial mean effective stresses $\mathrm{p}_{\mathrm{o}}$ close to those applying in-situ at their sampling depths, and (ii) those taken to significantly higher or lower p' values. Figure 5(a) shows the relationships between $\mathrm{Euv}_{\mathrm{sec}}$ and $\mathrm{p}_{\mathrm{o}}$ determined at three strain levels in tests run after reconsolidation to in-situ stress conditions. These experiments from the IC-T5-07 and QM series were sheared undrained after prolonged pause periods that allowed the creep strains to dissipate. At axial strains of $0.001 \%$, Euv $\mathrm{sec}$ depends on $\mathrm{p}_{\mathrm{o}}$ ' raised to the power 0.95 , which is broadly compatible with the linear $\mathrm{p}_{\mathrm{o}}$ normalisation applied in Figure 1 and consistent with the finding that elastic stiffnesses interpreted from downhole and crosshole shear wave tests correlate linearly with $\mathrm{p}_{\mathrm{o}}$ ' in London Clay (Hight et al., 2002). The dimensions of the Y1 elastic yield surface (defined in q, p' stress space) applying under in-situ stresses have also been shown by Gasparre et al (2007) to scale linearly with $\mathrm{p}_{\mathrm{o}}$ as they grow with increasing depth.

In contrast, triaxial and bender element experiments tests run at higher or lower stresses than act in-situ show much flatter stiffness-p' relationships and lower exponents (Gasparre et al 2007). Figure 5(b) shows the values of Euv $\mathrm{vec}_{\mathrm{sec}}$ at axial strains of $0.001 \%$ measured in $10 \mathrm{kPa}$ undrained compression probes on a sample as it was swelled from the estimated in-situ $\mathrm{p}_{\mathrm{o}}$ to lower values, while maintaining the insitu deviator stress $\mathrm{q}=60 \mathrm{kPa}$. At axial strains of $0.001 \% \mathrm{Euv}_{\mathrm{sec}}$ depends now on $\mathrm{p}$ ' raised to the power 0.35 The latter response reflects the effects of time and lithification on the soil structure, which make elastic stiffness far less sensitive to the changes in $\mathrm{p}$ imposed in the laboratory than those sustained over geological time scales.

However, the Euv ${ }_{\text {sec }}$ and p' ${ }_{o}$ power-law relationships found in tests run from in-situ stresses show flatter slopes and lower exponents as strains increase, suggesting that linear normalisation may not be appropriate at all strains, even in tests run from insitu stresses. The trends shown in Figure 5 differ from results obtained with other natural and reconstituted clays where the power law exponents were found to increase with strain level (Jardine 1995, Viggiani \& Atkinson, 1995). 
It follows that part of the difference between the normalised data sets in Figure 1 could have arisen as a result of errors in the estimated value for $\mathrm{p}_{\mathrm{o}}$ at each depth as this will have created differences in both the measured stiffness at small strains and in the normalised values. Under-estimating $\mathrm{p}_{\mathrm{o}}$, would lead to Euv $\mathrm{sed}_{\mathrm{p}} / \mathrm{p}_{\mathrm{o}}$ over-estimates and vice-versa.

\section{Effects of strain rate}

Figure 6 shows the stress-strain curves and the stiffness response at small strains of undrained triaxial compression stress probes performed at strain rates of $0.02 \% / \mathrm{h}$, $0.05 \% / \mathrm{h}$ and $0.25 \% / \mathrm{h}$ on the same sample. Each probe was carried out controlling the internal strain rates through the average value of the local strains, so achieving approximately constant rates of local strain despite apparatus compliance (Figure 6(a)). The probes were performed from the same anisotropic stress state and consisted of undrained incremental axial compressions of about 10kPa (Figure 6(b)). Undrained unloading followed each compression probe to return the sample to the initial stress state. The sample was then left to rest under constant effective stresses so that creep rates prior to shearing were lower than $0.0001 \% / \mathrm{h}$ for each probe. There is no systematic effect of strain rate on stiffness response at strains lower than $0.005 \%$ (Figure 6(c)). These findings are consistent with those of Tatsuoka et al. (1998) and Santucci de Magistris (1998), namely that at very small strains the elastic stiffness of a number of stiff clays is hardly influenced by strain rate.

At larger strains step changes of strain rates are known to affect the stiffness response, see, for example, Sorensen at al. (2007) for London Clay and Tatsuoka et al. (1998) for a range of stiff clays.

\section{Effects of creep rates prior to undrained shear}

Jardine (1985 and 1992) pointed out that any creep that persists at the end of a consolidation or swelling stage will modify the measured stiffness, especially at very small strains. He recommended that there should be a ratio of 100 between shear strain and creep strain rates in order to minimise such effects. Figure 7(a) shows the stiffness response of a sample sheared undrained at a rate of $0.2 \% / \mathrm{h}$ after a prolonged creep period, compared with the stiffness response of the same sample sheared undrained at the same rate, but without an intervening long rest period. In the latter case the creep rate prior to shear remained around $0.2 \% / \mathrm{h}$. In both cases the (q-p') effective stress path followed in undrained shear was inclined at 90 degrees to the direction of the approach reconsolidation effective stress path. The effect of ongoing creep after a change in stress path direction is clearly extremely important at small strains (in this case less than $0.004 \%$ ).

Figure 7(b) shows the relationship between the elastic stiffness and the ratio of shear to creep strain rates found in selected IC-T5-07 and QM tests. In these tests the effective stress path direction during undrained shear had the same inclination as the approach stress path. The strain rates were calculated using data from the local instrumentation. The measured stiffness values are normalised by a reference small strain stiffness, which is taken here as Euv $/ p^{\prime}{ }_{0}=650$. Elastic stiffness increases with the ratio of shearing to creep axial strain rate and significant errors occur when the 
true (locally measured) ratio is less than 40. Jardine's (1985) recommendation of a ratio of 100 should be followed to ensure an error of no more than $1 \%$.

The rest time and ratio between undrained shear rates and residual creep rates are therefore important parameters and these will be addressed subsequently in assessing their contribution to the differences between the IC-T5-07 and T5-00 data sets.

\section{Effects of recent stress and strain history}

The dependency of the stiffness response of clays on recent stress history has been reported by several authors as resulting from changes in the direction of the stress path (Atkinson, 1973, Costa Filho, 1984, Atkinson et al., 1990, Jardine, 1992, Stallebrass \& Taylor, 1997, Lings et al., 2000), or the abrupt start of loading following a period of rest (Som, 1968, Sorensen et al., 2007). Gasparre et al. (2008) identified a relationship between the small-strain stiffness behaviour of London Clay and its recent history of yielding and creep rate dissipation (or ageing). They found that provided samples had not engaged a second KYS (termed Y2 which leads to increasingly plastic features of stress-strain behaviour, as described by Jardine 1992 and 2013) while moving along their approach effective stress paths, extended creep pause periods could erase the latter's influence on the behaviour observed along the outgoing path. However, when Y2 yielding (and KYS relocation) had developed during the approach stage, even extended creep periods could not erase the stress history dependence. The stiffness characteristics depended on the angle of rotation, $\theta$, between the approach and outgoing stress paths, with the stiffest behaviour being seen for highest $\theta$.

Whether or not the Y2 surface is engaged, and therefore whether soil stiffness is modified, is related to the strain levels reached during reconsolidation. The strain histories of the two sets of T5 tests are considered subsequently to see whether they contributed to the divergence between the stiffness data.

\section{Factors affecting the measured stiffness characteristics of London Clay and their contribution to the divergence between the two data sets}

\section{Sample quality}

Advanced triaxial tests on natural soils are expensive and tests should be made on the highest quality samples that can be taken. It is vital that sampling minimises the strains imposed and preserves the intact structure.

Both the original and new test programmes were carried out on rotary core samples which were preserved in the same way. There is no evidence from post-sampling suction and shear wave measurements of any difference in quality. The strains which developed during reconsolidation are discussed below.

\section{Sample preparation and setting}


Hydraulic triaxial apparatus and similar sample preparation techniques were used for the T5-00 and IC-T5-07 tests. However, despite the care taken when trimming the $100 \mathrm{~mm}$ diameter samples, it is extremely difficult with stiff fissured clays to ensure precisely flat and parallel ends. A degree of random non-uniformity in sample end conditions, which will result in varying bedding effects and compliance, is inevitable. As discussed below, this random non-uniformity contributed to the difference between the data sets.

In both test programmes extreme care was taken in ensuring that the local axial displacement transducers were fitted over an accurately known gauge length.

\section{Pressure and temperature control}

The pressure controllers employed for the IC-T5-07 tests were set to maintain stresses within $\pm 0.1 \mathrm{kPa}$ of their target value, while $\pm 1 \mathrm{kPa}$ tolerances were typical for the T500 tests. However, there is no evidence that the T5-00 test results were affected significantly by any oscillation of pressures.

Temperature variations can also impact small strain stiffness measurements (Gasparre \& Coop, 2006). Since both test series were carried out in temperature controlled rooms, temperature fluctuations are unlikely to be a factor contributing to the different T5 stiffness measurements.

\section{Effect of load cell to sample connection}

Figure 8(a) shows the data obtained from an undrained triaxial compression test performed on a $100 \mathrm{~mm}$ diameter rotary core specimen taken from $8 \mathrm{~m}$ below the top of the London Clay at the QM site. Figure 8(a) presents the stress-strain data obtained from the two local axial displacement transducers, the external axial displacement transducer, and the average from the two local transducers. The tangent and secant undrained vertical moduli derived from the average of the two local transducer readings and normalised by $\mathrm{p}{ }_{\mathrm{o}}$ are shown in Figure 8(b) and follow similar trends to those measured in the IC-T5-07 tests, an example of which is shown in Figure 4.

The QM test was run in a similar manner to the IC-T5-07 tests, using a connection between the internal load cell and top platen which involved a $100 \mathrm{~mm}$ diameter suction cap and half ball which protrudes $1 \mathrm{~mm}$ above the top platen (Figure 9(c)). Grease was applied between the half ball and the top platen to minimise friction. This detail led to reasonable agreement between the two local transducer readings at small and medium strains. There was also general agreement between the local and external transducer readings indicating a stiff system with limited seating, compliance and bedding effects.

Figure 10(a) shows the equivalent data from an undrained triaxial compression test on a $100 \mathrm{~mm}$ diameter sample from $32.5 \mathrm{~m}$ below the top of the London Clay. This test was also carried out in the same apparatus of the IC-T5-07 tests but using a rigid connection in which the top platen of the sample is screwed directly to the load cell, as shown in Figure 9(a). In this test and in a number of other tests with a rigid connection the two local transducers showed disagreement, with one of the transducers not appearing to respond until a significant deviator stress had been applied. For the test shown in Figure 10 a deviator stress of $30 \mathrm{kPa}$ had been applied 
before one of the local transducers responded. The curve of secant and tangent and shows an initially stiff response and then a kink as the second local transducer starts moving freely under stress. The stiffness interpreted from this non-uniformly loaded sample is significantly higher than that of other nearby samples taken and tested in the same manner in which the local transducers moved together from the start of loading.

Figure 11 shows the equivalent data from an undrained triaxial compression test on a $100 \mathrm{~mm}$ diameter sample from $21 \mathrm{~m}$ below the top of the London Clay. Again this test was run in the same apparatus as the IC-T5-07 tests but using the load cell-top platen connection shown in Figure 9(d), i.e. a half ball without the suction cap. In this case the divergence between the two local transducers is even greater, with them moving in opposite directions initially, presumably as a result of the sample tilting under load.

Each of these tests was carried out in the same laboratory using similar apparatus, procedures and instrumentation but different types of load cell connection, demonstrating that the means of application of vertical load can lead to marked differences in the apparent stiffness of stiff clays. The patterns of strains in Figures 10 and 11 suggest that the two transducers record the true local strains in the samples (within the limits of their resolution) and that straining varies considerably across the sample. Loading eccentricity that imposes bending moments is the most likely cause. In Figure 11 the measured stiffness increases initially as one of the transducers indicates tensile straining, it then reduces when the two transducers both follow compressive trends.

The risk of eccentric loads being applied to the sample and causing divergence of the local transducer readings appears to be much greater with rigid or pin connections than with a suction cap and half ball connection. The latter appears to minimise the effects of any apparatus misalignment and unavoidable imperfections in trimming or in setting up the sample on the pedestal by the half-ball rotating, adapting its direction to the load cell and avoiding the disturbance caused by imposing the alignment. On the other hand the rigid and pin connections appear to be sensitive to bedding and alignment imperfections and to result in the application of non-co-axial or nonuniform loads to the sample when these imperfections are present.

In the IC-T5-07 and QM tests shown in Figure 1 the suction cap and half ball was used whereas the original T5-00 tests were run using the connection shown in Figure 9(e), which is likely to have had similar issues to those discussed above with the connection shown in Figure 9(d). The majority of the commercial tests used to develop the database shown in Figure 1 were run with the top cap detail shown in Figure 9(e) or with the rigid connection shown in Figure 9(a) if triaxial compression and extension stages were involved. For compression only tests the detail shown in Figure 9(b) was used, in which the load cell carried a protruding pin which fitted into the top platen. This key difference between the load cell to platen connection provides one of the main contributing factors to the difference between the IC-T5-07 and T5-00 data sets at small strains.

\section{Effect of reconsolidation paths}


In the IC-T5-07 and T5-00 tests the samples were reconsolidated to their estimated in situ stress states prior to undrained shear, following a path which retraced the most recent geological history that the samples had experienced in situ, namely unloading by erosion followed by reloading when the River Terrace Deposits accumulated. In the IC-T5-07 test series the changes in cell pressure and axial stress were applied at rates which were sufficiently slow to ensure that any excess pore pressures did not exceed 5\% of the current mean effective stress, p'. In the T5-00 tests isotropic consolidation stages were carried out by changing the cell pressure in one step and letting the sample drain. On large samples this practice creates important non-uniform pore pressure distributions in the sample, which prevent any reliable correlation between mean effective stress and volume strain, i.e. bulk modulus, being derived. However, anisotropic consolidation stages were carried out in the T5-00 tests by changing the axial stress and cell pressure in steps that did not exceed $5 \mathrm{kPa}$.

The axial and volumetric strains which developed during reconsolidation to in situ stresses in each test are shown in Table 1. The strains in most cases are significantly less than $1 \%$, confirming that the quality of the samples was reasonable. In two cases the strains in the T5-00 tests are higher than the IC-T5-07 and QM tests and, if evidence of damage, would be expected to lead to lower measured stiffnesses at small strains. Table 1 shows this was not the case so that differences in recent strain history cannot explain the differences in the stiffnesses measured.

\section{Effects of undrained axial strain rates and preceding creep strain rates}

The IC-T5-07 tests on samples from $30.1 \mathrm{~m}$ and $32.7 \mathrm{~m}$ below the top of the London Clay were carried out under stress control up to strains of approximately $0.1 \%$, after which an external strain rate of about $0.05 \% / \mathrm{h}$ was imposed. These tests developed strain rates between approximately 0.005 and $0.01 \% / \mathrm{h}$ over their initial linear portions (Table 1). The IC-T5-07 test on the sample from $6.5 \mathrm{~m}$ was run with local strain rates of $0.01 \% / \mathrm{h}$ up to $0.1 \%$ strain and $0.02 \% / \mathrm{h}$ thereafter. The QM tests were run at a range of local strain rates over their elastic regions, as listed in Table 1.

The undrained shearing stages of the T5-00 test series were carried out using an externally controlled constant displacement rate which gave a notional constant axial strain rate of $0.2 \% / \mathrm{h}$. However, due to compliance effects the axial strain rates based on the local instrumentation were between $0.01 \% / \mathrm{h}$ and $0.05 \% / \mathrm{h}$ at small strains (see Table 1), with local and external strain rates converging as the tests continued and bedding/compliance errors became less important, as illustrated in Figure 12.

Since there is little or no effect of strain rate on stiffness at very small strains, as confirmed in Figure 6, differences in strain rates evident in Table 1 and Figure 12 cannot explain the divergence of measured stiffnesses between the two test series at very small strains seen in Figure 2. At strains larger than $0.1 \%$ Figure 2 shows good agreement in modulus decay between samples from similar depths, suggesting that the strain rate effect may not be large above $0.1 \%$.

Prior to undrained shearing the axial creep strain rates in the IC-T5-07 tests shown in Figure 1 were less than $0.0002 \% / \mathrm{h}$ so that the ratio between the shearing and creep axial strain rates was always greater than 47 and little effect should be expected on the basis of Figure 7(b). 
In the T5-00 series axial creep strain rates prior to undrained shear were around $0.0015 \% / \mathrm{h}$, which corresponds to the resolution of the local instrumentation being used at that time. However, because of apparatus compliance and bedding the internal strain rate was considerably lower than the nominal externally applied strain rate, as shown in Figure 12. As a result in some cases the ratios of shearing to creep axial strain rates were lower than intended, see Table 1, so that stiffnesses measured in tests that had involved stress path reversals (such as triaxial compression following reconsolidation to $K_{0}>1$ ) would have been overestimated, as is the case in Figure 2(a), while stiffnesses measured in tests conducted without stress reversal would have been underestimated, as in the case of Figure 2(b).

The different ratios of shearing to creep axial strain rates are a second important contributory factor in the divergence between the stiffnesses measured at small strains in the two test series.

\section{Detailed review of the original T5-00 data set}

Figures 13 and 14 show two examples of the T5-00 data set in the form of the deviatoric stress changes plotted against axial strains derived from the two local displacement transducers and from the external transducer, together with the secant and tangent stiffness values derived from the average of the internal strains and normalised by p' ${ }_{\mathrm{o}}$. The T5-00 tests have two main features in common. The first is the limited resolution of the local instrumentation system. Each transducer record shows regular steps of $0.0015 \%$, corresponding to the resolution of the measurement system.

The IC-T5-07 and QM tests were carried out using LVDTs similar to those developed by Cuccovillo \& Coop (1997) and read with a more capable analogue to digital converter leading to a system that could resolve strain increments smaller than $0.0001 \%$. The difference in resolution of the local axial displacement measurement system used in the IC-T5-07 and T5-00 test series is a third significant contributor to the difference in the measured stiffnesses.

The second feature of the T5-00 tests (Figure 13) is a significant discrepancy between the strains derived from the two local transducers and between these and the values derived from the external axial displacement transducer. In some cases no strains were recorded by one or both transducers for increments in deviator stress up to $20 \mathrm{kPa}$. As a consequence of these measurements the secant stiffness at small strains calculated from the average of the local transducers is higher than that of the similar sample shown in Figure 2(a). These discrepancies are almost certainly the result of using the connection between the load cell and top platen shown in Figure 9(e), together with the low ratio of shear to creep strain rates in a test involving stress reversal.

The normalised secant stiffnesses calculated using an average of the local transducer readings are strongly affected by the behaviour at the start of the test and by the poor resolution of the stress-strain data at small strains (Figure 13(b)); starting from impossibly large initial values the normalised stiffnesses tend to reduce steadily with increasing strain. The normalised tangent curves have different trends because they are less affected by the behaviour at the start of the tests. The comparison in terms of 
secant stiffnesses in Figure 1 tends, therefore, to exaggerate the differences between the two data sets.

The stress-strain data from another T5-00 test, this time for a sample from $10.29 \mathrm{~m}$ depth, is shown in Figure 14 and displays the same resolution limitations as in Figure 13. However, in this case the two local transducers record similar values and move together from the start of the load application. The normalised secant and tangent stiffness curves for this test coincide at small strains and they are similar to the IC-T507 curves. Figures 13 and 14 illustrate the random nature of the alignment that is achieved between sample and load cell unless a suitable connection is used.

\section{Manipulation of the measured data}

It appears to be common practice to average the strain values derived from the two local transducers when calculating stiffness. However, when the two local transducers are in disagreement (Figures 10 and 11, for example) their average value may not be representative of a uniform strain and stress distribution across the sample. When performing axial compression or extension tests the agreement between the response of the local transducers at small and medium strains is therefore a good indicator that axial loads only are being applied to the sample. As the load increases towards the peak strength, non-uniformities in the distribution of strains would be expected due to localization of strains and the local transducers could measure different values. It must also be recognised that with only two local axial displacement transducers there is still a possibility that bending of the sample is occurring about the axis on which the two transducers have been placed. Installing three sensors set at $120^{\circ}$ angles would address this potential problem.

Furthermore, if the resolution of the local instrumentation is poor the calculation of secant stiffness might give misleading trends. These calculations are significantly affected by the choice of the starting point for the test and as strains scatter around the zero or a very small value, the secant values calculated at each strain point scatter and in extreme cases reach negative values. Using a logarithmic strain scale the pattern is altered because the negative values disappear, resulting in a distorted trend for the curve. It is far better practice to use arithmetic stress strain plots to evaluate stiffness over the initial, most highly scattered, sections of the tests.

\section{Concluding remarks}

The measurement of stiffness at small strains in advanced triaxial tests requires high resolution local instrumentation, stable control of pressures and temperature, good alignment of sample and apparatus, and precision in the application of the axial load. The resolution of the instrumentation to measure axial displacements locally should be at least one order of magnitude smaller than the strain level being measured. When computational software is used for the calculation of secant stiffness the derived values are affected by the first data point and judgment should be applied in establishing the start of the test. The use of the connections between the internal load cell and sample top platen shown in Figures 9(a), (b), (d) and (e) should only be used if perfect alignment between the sample and apparatus can be guaranteed, otherwise there is the risk of eccentric axial loads being applied to the sample, 
It is critically important to ensure that creep rates prior to shear do not influence the shearing stage. This requires exceeding a minimum ratio between the actual strain rate during undrained shear and the creep rate prior to shear. The ratio of 100 originally proposed by Jardine et al. (1984) should be adopted. It is essential that the strain rate during shear is either controlled or checked using the internal strain measurements since bedding and compliance effects can reduce significantly the controlled external displacement rate.

In the interpretation of test data from advanced triaxial tests which are aimed at measuring stiffness at small strains attention should be paid to the behaviour of all local transducers at the start of the tests and the following conditions should be used as acceptance criteria for the tests:

- The readings from all local displacement transducers are consistent (and compatible with the applied loading data) up to at least $0.01 \%$ axial strain.

- The values of secant and tangent stiffnesses should coincide at very small strains. Provided that the local transducers are in agreement the tangent stiffness values can be considered more indicative of the evolving stress-strain behaviour, provided they can be resolved reliably over the full strain range.

The practice of averaging different displacement readings from two local transducers can lead to significant misinterpretation of the soil stiffness response if these criteria are not met.

The stiffnesses measured in the two test programmes, IC-T5-07 and T5-00, differ most markedly at strains less than $0.1 \%$. Within this small strain range, measurements are sensitive to the ratio of undrained shear strain rate to creep strain rate, to a combination of imperfections in sample geometry and the connection between the internal load cell and sample top cap, and resolution of the local axial displacement transducers. Increased resolution of the instrumentation, a modified connection detail and better control over the ratio of undrained shear to creep strain rates in the IC-T507 test series, have led to more reliable measurements of stiffness at these very small strains. It must be emphasised that since the T5-00 test data was obtained there have been significant improvements in the resolution of strains and of signal conditioning in commercial laboratories.

This paper has considered only the measurement of undrained vertical stiffness in triaxial compression tests. Similar considerations apply to the measurement of stiffness in undrained triaxial extension tests. It should also be recalled that the undrained horizontal stiffness of London Clay is significantly higher than the undrained vertical stiffness at small strains ((Gasparre et al., 2007) and at relatively large strains (Ward et al. (1965) and Bishop et al. (1965)).

\section{Acknowledgements}

The Authors acknowledge gratefully the support provided for the work described by British Airports Authority and the UK Engineering and Physical Sciences Research Council, as well as the contributions of current and former colleagues, particularly 
Drs Nishimura and Minh, at Imperial College where the experiments were performed. The authors would also like to thank Chris Russell of Russell Geotechnical Innovations for his assistance in the preparation of the paper.

\section{REFERENCES}

Atkinson J. H. (1973). The deformation of undisturbed London Clay. PhD. Thesis, Imperial College of Science, Technology and Medicine, University of London. Atkinson J.H., Richardson D. \& Stallebrass S.E. (1990). Effect of stress history on the stiffness of overconsolidated soil. Géotechnique 40, No.4, 531-540.

Bishop A.W., Webb D.L. \& Lewin P.I. (1965). Undisturbed samples of London Clay from Ashford Common shaft: strength-effective stress relationships. Géotechnique 15, No.1, 1-31.

Costa Filho L.M. (1984). Technical note: A note on the influence of fissures on the deformation characteristics of London Clay. Géotechnique 34, No.2, 268-272.

Cuccovillo T. \& Coop M.R. (1997). The measurements of local axial strains in triaxial tests using LVDTs. Géotechnique 47, No. 1, 167-171.

Gasparre A., Nishimura S., Minh N.A., Coop M.R. \& Jardine R.J. (2007). The stiffness of natural London Clay, Géotechnique 57, No. 1, 33-47.

Gasparre A., Coop M.R. \& Jardine R.J. (2008). Effects of recent stress history on a stiff clay. Proceeding of the Fourth International Symposium on Deformation Characteristics of Geomaterials (eds. Burns, Mayne and Santamarina), 207-213. Atlanta.

Gasparre, A. \& Coop, M.R. (2006). Technical Note: Techniques for performing small strain probes in the triaxial apparatus. Géotechnique 56, No. 4, 491-495.

Hight, D.W. (1982). Technical Note: A simple piezometer probe for the routine measurement of pore pressure in triaxial tests on saturated soils. Géotechnique 32, No 4, 396-401.

Hight D.W., McMillan F., Powell J.J.M., Jardine R.J. \& Allenou C.P. (2002). Some characteristics of London Clay. In Characterisation and engineering properties of natural soils (eds. T.S. Tan, K.K. Phoon, D.W. Hight and S. Leroueil), 851-908. Rotterdam: Balkema.

Hight D.W., Gasparre A., Nishimura S., Minh N.A., Jardine R.J. \& Coop M.R., (2007). Characteristics of the London Clay from the Terminal 5 site at Heathrow Airport. Géotechnique 57, No. 1, 3-18.

Jardine R.J., Symes M.J. \& Burland J.B. (1984). The measurement of soil stiffness in the triaxial apparatus. Géotechnique 34, No.3, 323-340.

Jardine R.J. (1985). Investigation of pile-soil behaviour with special reference to the foundations of offshore structures. PhD Thesis, University of London.

Jardine R.J. (1992). Some observations on the kinematic nature of soil stiffness. Soils and Foundations 32, No. 2, 111-124.

Jardine, R J (1995). One perspective on the pre-failure deformation characteristics of some geomaterials. Keynote lecture. Proc. International Symposium on pre-failure deformation characteristics of geomaterials. Hokkaido, Japan, Volume II, 885-886. Jardine, R.J. (2013). Advanced laboratory testing in research and practice. $2^{\text {nd }}$ Bishop Lecture. Proc. ICSMGE, Paris, Presse des Ponts. Vol 1, 35-55

King C. (1981). The stratigraphy of the London Basin and associated deposits. Tertiary Research Special Paper 6, Rotterdam: Backhuys. Lings M.L., Pennington D.S. \& Nash D.F.T. (2000). Anisotropic stiffness parameters and their measurement in a stiff natural clay. Géotechnique 50, No.2, 109-125. 
Nishimura, S., Anh-Minh, N. \& Jardine, R.J. (2007). Shear strength anisotropy of natural London Clay. Géotechnique 57, No.1, 49-62.

Pennington D.S., Nash D.F.T. \& Lings M.L. (1997). Anisotropy of Go shear stiffness in Gault Clay. Géotechnique 47, No.3, 391-398.

Santucci de Magistris F. (1998). Internal report. Geotechnical Engineering

Laboratory, University of Tokyo.

Som N.N. (1968). The effects of stress path on deformation and consolidation of London Clay. PhD Thesis, University of London.

Sorensen, K.K., Baudet, B. A. \& Simpson, B. (2007). Influence of structure on the time-dependent behaviour of a stiff sedimentary clay. Géotechnique 57, No 1, 113124.

Stallebrass S.E. \& Taylor R.N. (1997). The development and evaluation of a constitutive model for the prediction of ground movements in overconsolidated clay.

Géotechnique 47, No.2, 235-353.

Tatsouka F., Santucci de Magistris F., Hayano K., Momoya Y. \& Koseki J. (1998). Some new aspects of time effects on the stress-strain behaviour of stiff geomaterials. Keynote lecture in the 2nd International Symposium on Hard Soils and Soft Rocks, Napoli (eds. A. Evangelista and L. Picarelli), 1-87. Balkema

Viggiani G. \& Atkinson J.H. (1995) Stiffness of fine grained soil at very small strains. Géotechnique 45, No.2, 249-265.

Ward W.H., Marsland A.\& Samuels S.G. (1965). Properties of the London Clay at the Ashford Common shaft: in-situ and undrained strength tests. Géotechnique 15, No.4, 321-344. 


\begin{tabular}{|c|c|c|c|c|c|c|c|c|}
\hline \multirow[t]{2}{*}{$\begin{array}{c}\text { Test } \\
\text { series }\end{array}$} & \multirow[t]{2}{*}{$\begin{array}{l}\text { Depth } \\
\text { below top } \\
\text { of } \\
\text { London } \\
\text { Clay }(\mathrm{m})\end{array}$} & \multicolumn{2}{|c|}{$\begin{array}{l}\text { Local strains } \\
\text { developed over } \\
\text { the approach } \\
\text { stress path [\%] }\end{array}$} & \multicolumn{2}{|c|}{$\begin{array}{l}\text { Stress state prior } \\
\text { to shearing [kPa] }\end{array}$} & \multirow[t]{2}{*}{$\begin{array}{c}\text { Average } \\
\text { local axial } \\
\text { strain rate } \\
\text { up to } 0.1 \% \\
\text { strains } \\
{[\% / h]} \\
\end{array}$} & \multirow[t]{2}{*}{$\begin{array}{c}\text { Local } \\
\text { shearing/ } \\
\text { creep axial } \\
\text { strain rate } \\
\text { ratio } \\
\end{array}$} & \multirow[t]{2}{*}{$\begin{array}{c}\text { Elastic } \\
\text { Euv }_{\text {sed }} / \\
\text { p'o }\end{array}$} \\
\hline & & $\varepsilon a$ & $\varepsilon v$ & $p^{\prime}$ & $q$ & & & \\
\hline \multirow{3}{*}{ IC-T5-07 } & 6.5 & 0.09 & 0.25 & 257 & -85 & 0.01 & 47 & 650 \\
\hline & 30.1 & 0.73 & 0.8 & 518 & -126 & $0.017^{*}$ & 52 & 545 \\
\hline & 32.7 & 0.71 & 1.1 & 502 & -121 & 0.005-0.01* & 60 & 600 \\
\hline \multirow{6}{*}{ QM } & $10 m-c 1$ & 0.1 & 0.64 & 324 & -99 & 0.04 & 50 & 650 \\
\hline & $10 m-p 5$ & 0.11 & 0.64 & 321 & -100 & 0.05 & 159 & 650 \\
\hline & $10 m-p 12$ & 0.11 & 0.64 & 323 & -99 & 0.2 & 73 & 650 \\
\hline & $8 m-c 1$ & 0.12 & 0.23 & 215 & -41 & 0.13 & 83 & 687 \\
\hline & $8 m-c 3$ & 0.14 & 0.23 & 215 & -42 & 0.22 & -418 & 680 \\
\hline & $8 m-c 5$ & 0.12 & 0.23 & 190 & 58 & 0.23 & -1636 & 690 \\
\hline \multirow{4}{*}{ T5-00 } & 4.3 & -1.5 & -1.2 & 253 & -55 & 0.04 & -27 & $>1000$ \\
\hline & 10.29 & -0.4 & 0.1 & 274 & -179 & 0.04 & 28 & 650 \\
\hline & 28.46 & 0.7 & 2.1 & 415 & -121 & 0.05 & 25.5 & $>1000$ \\
\hline & 41.05 & 0.0 & -0.1 & 542 & -101 & 0.01 & 6 & $>1000$ \\
\hline
\end{tabular}

*stress controlled

Table 1: Details of tests

(Negative shear/creep strain rates indicate that the preceding creep strains were in the opposite direction to the applied shear strains.) 


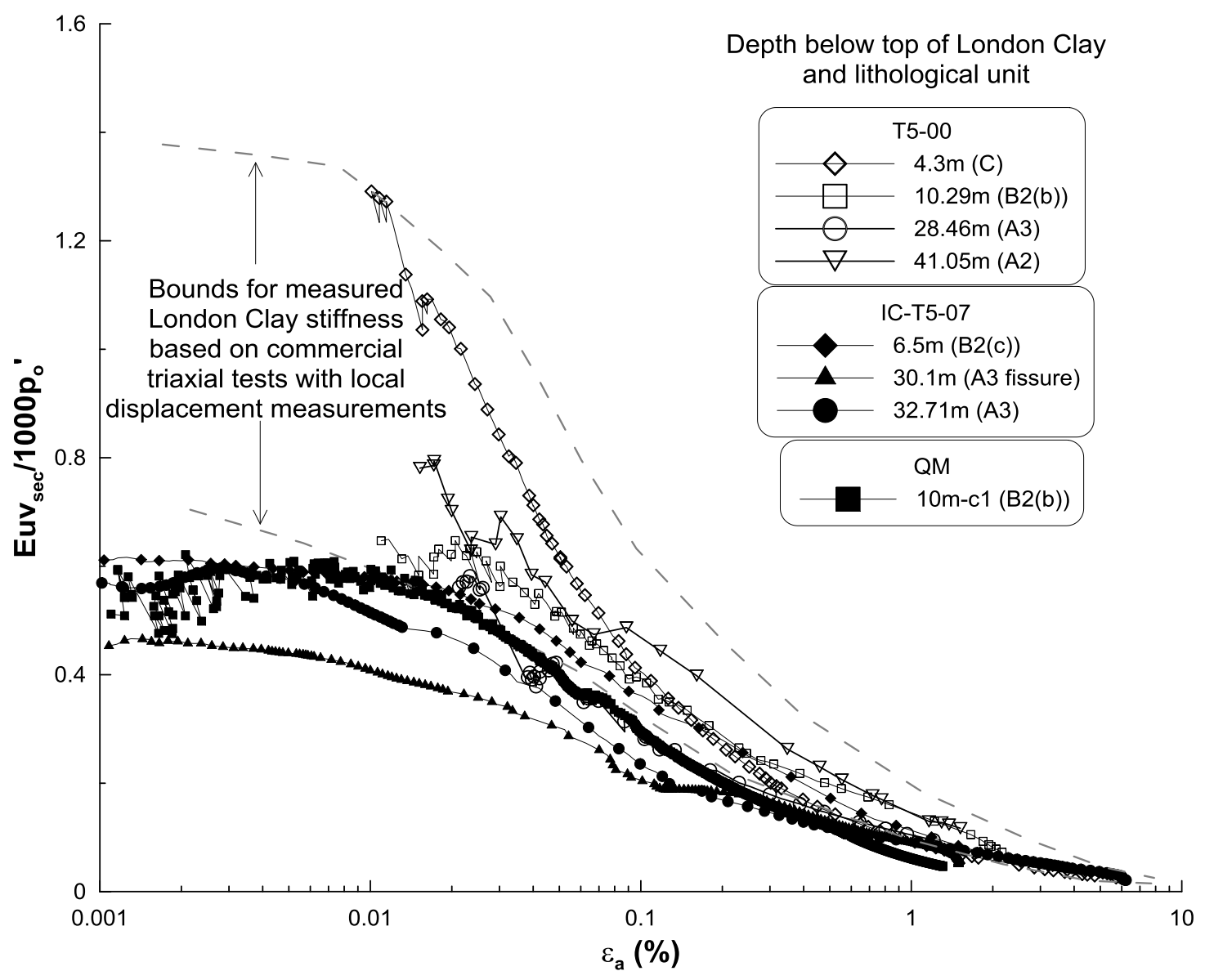

Figure 1: Comparison of normalised modulus decay curves for undrained triaxial compression of London Clay in different test series 

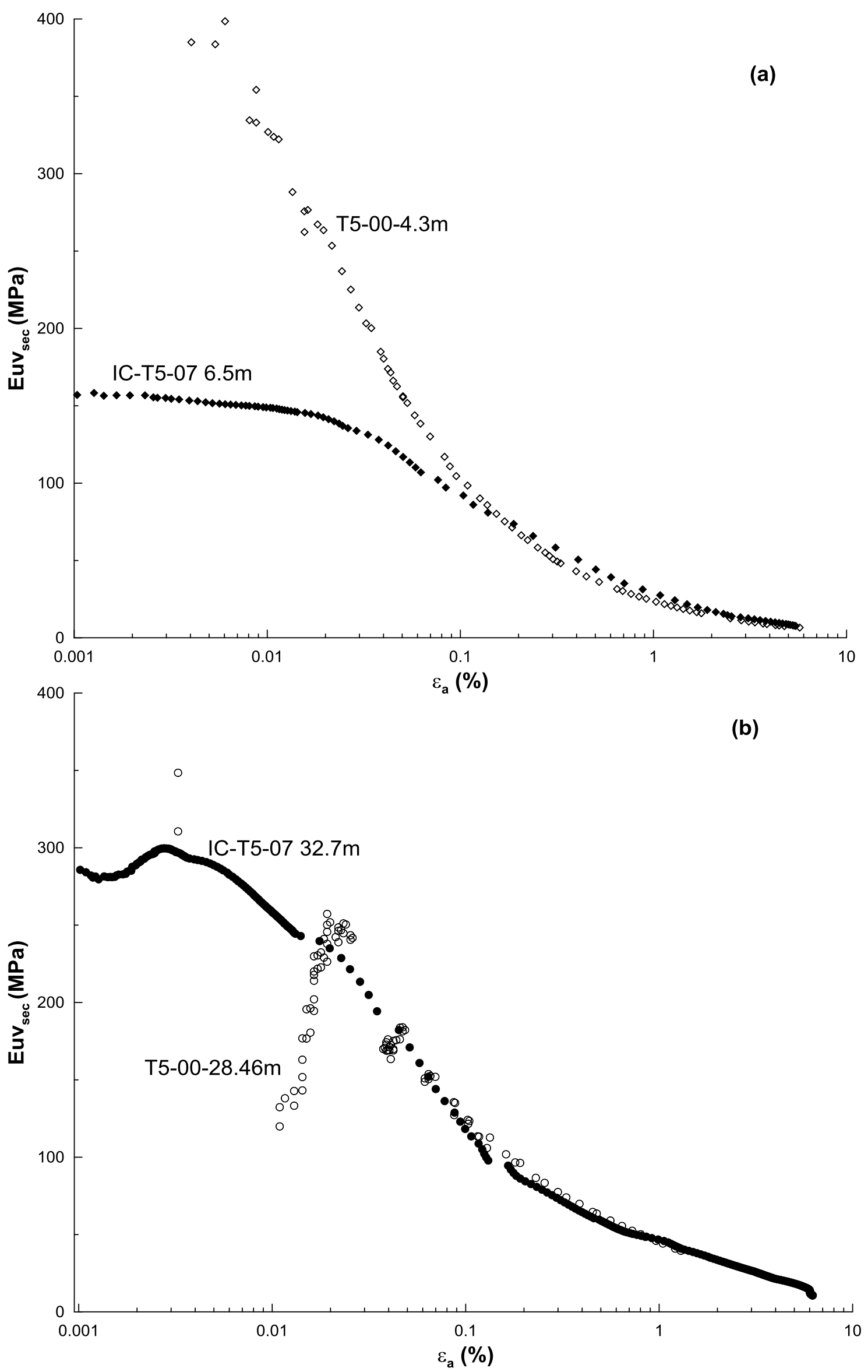

Figure 2: Comparison of modulus decay curves in undrained triaxial compression of London Clay samples from similar depths in T5-00 and IC-T5-07 test series (a) 4.3 and 6.5m, (b) 28.46 and 32.7m 


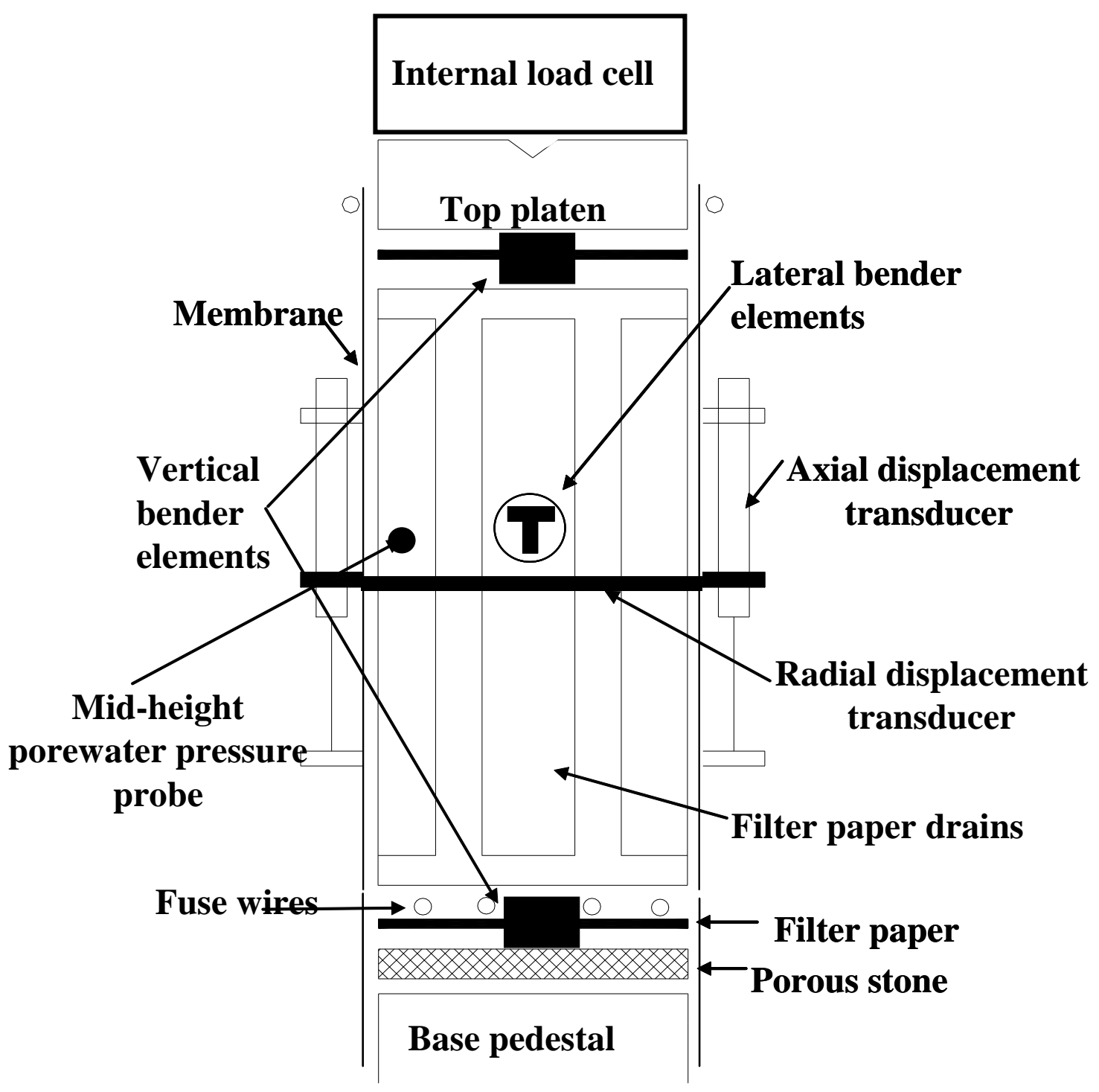

Figure 3: Typical arrangement of a sample for advanced triaxial testing 
(a)

(b)
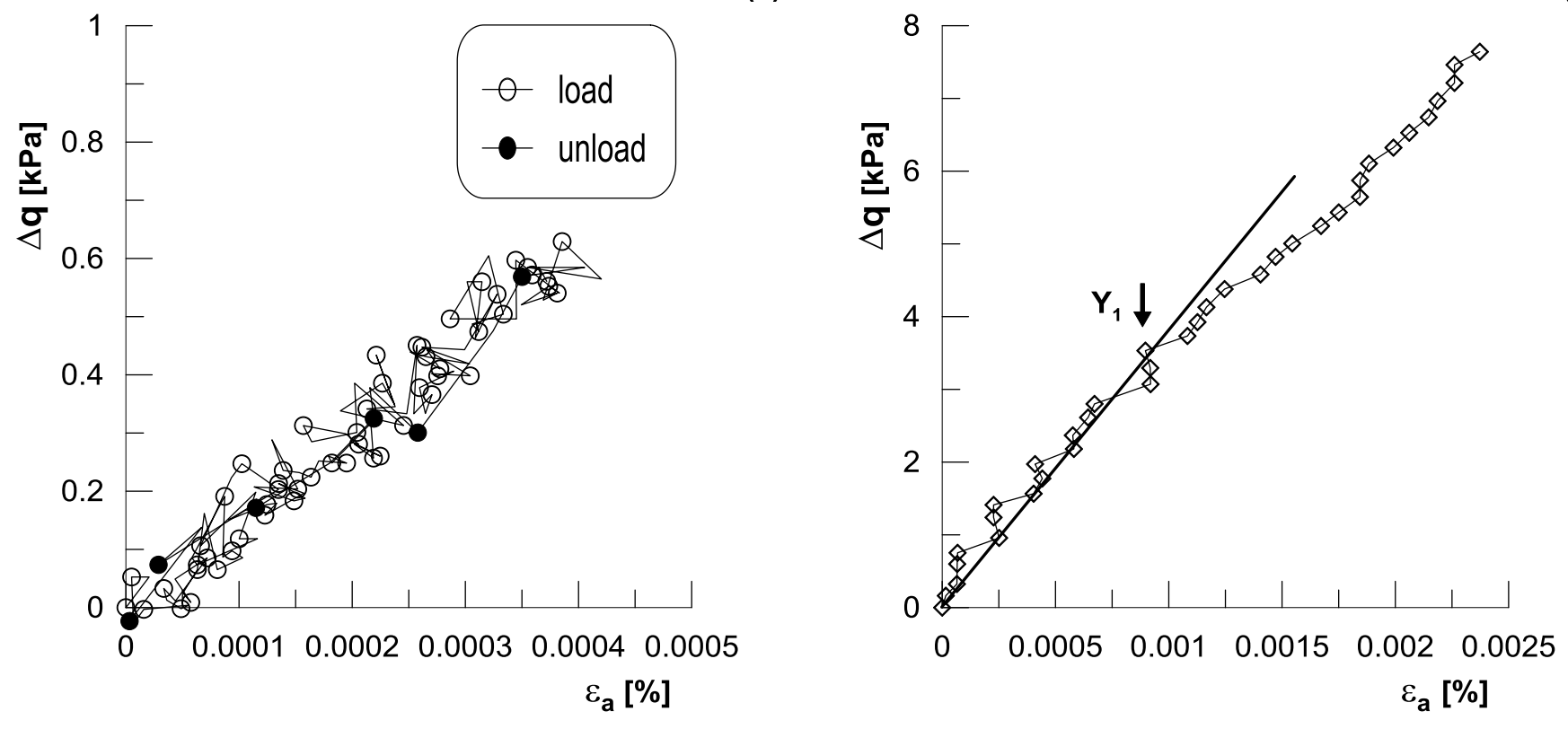

(c)

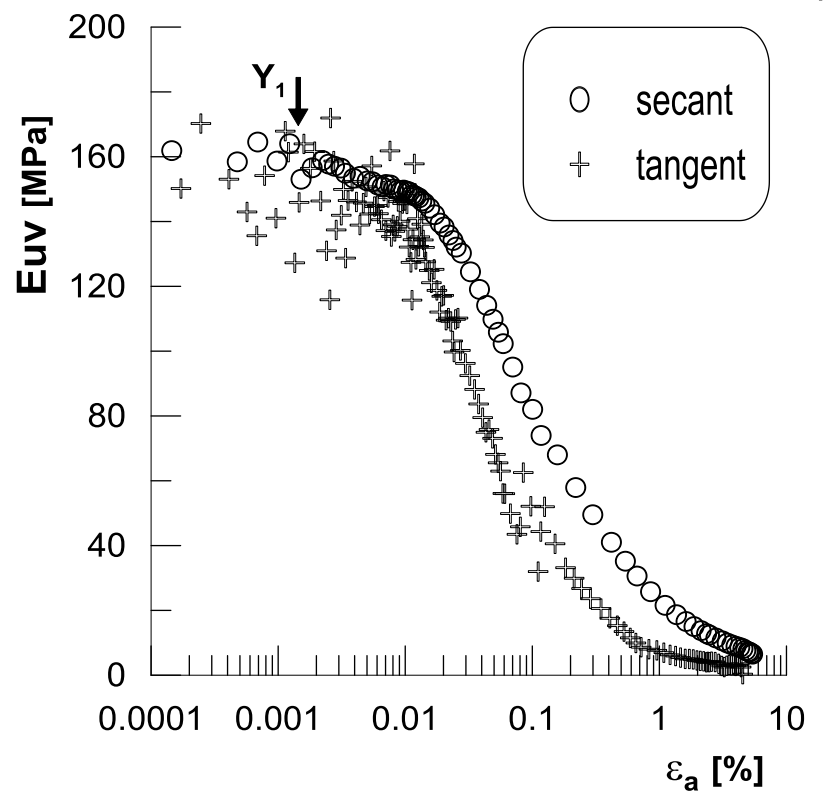

Figure 4: Typical undrained stress-strain behaviour of London Clay: (a) initial linear elastic response, (b) $\mathrm{Y} 1$ yield point, (c) decay curves of secant and tangent vertical stiffness, $E_{u v}$ 
(a)
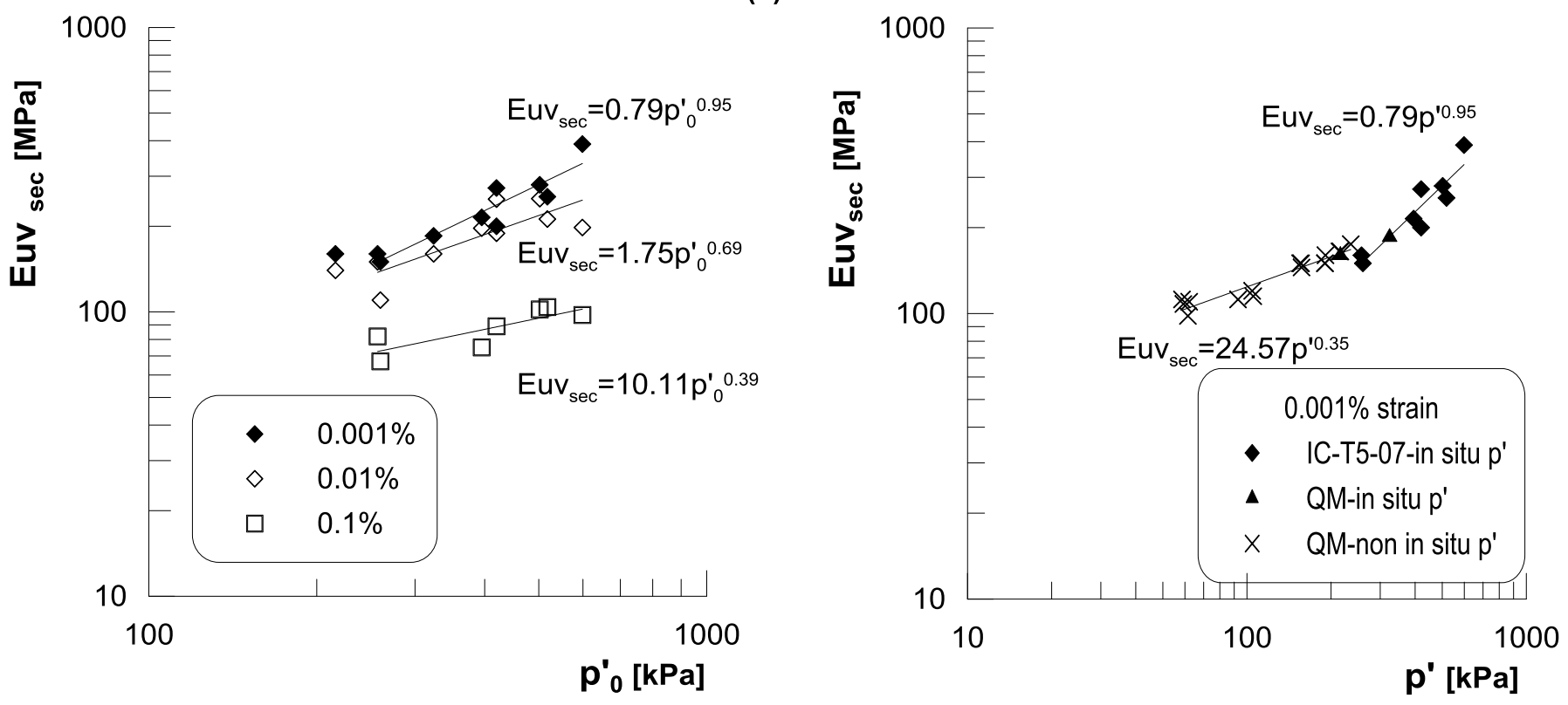

Figure 5: (a) Undrained vertical stiffness at different strain levels for samples consolidated to estimated $\mathrm{p}_{\mathrm{o}}{ }_{\mathrm{o}}$, (b) Undrained vertical stiffness at $0.001 \%$ strain for samples consolidated to estimated $p^{\prime}{ }_{\circ}$ and for a sample swelled to various $p^{\prime}$ values after consolidation to estimated $p^{\prime}$ 。 
(a)

(b)
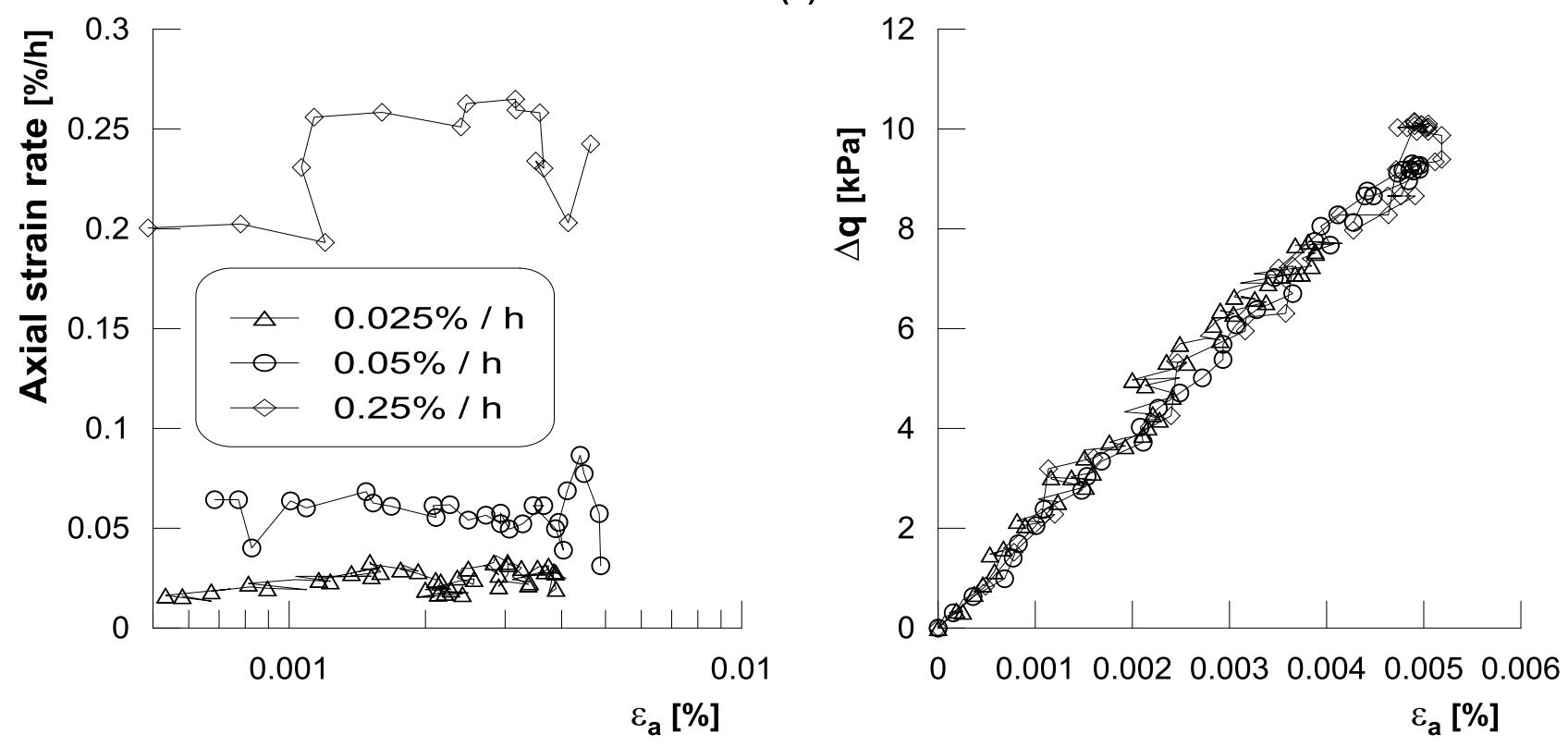

(c)

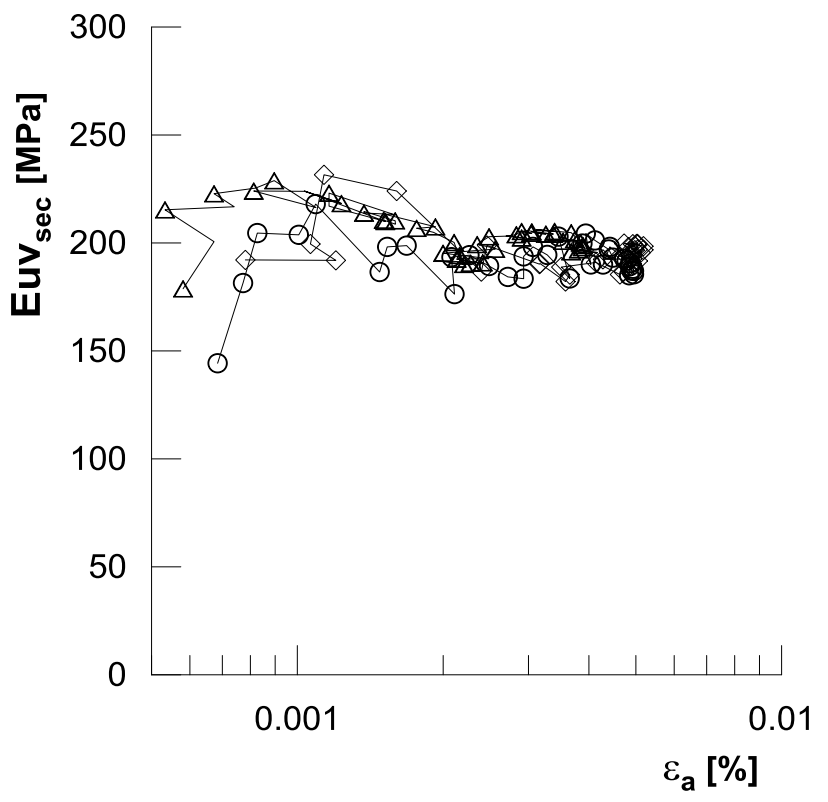

Figure 6: Probes on QM sample from 10m below top of London Clay sheared in undrained compression at different axial strain rates: (a) axial strain rate versus axial strain, (b) stress-strain data, (c) undrained secant vertical stiffness at different strains and strain rates 
(a)

(b)
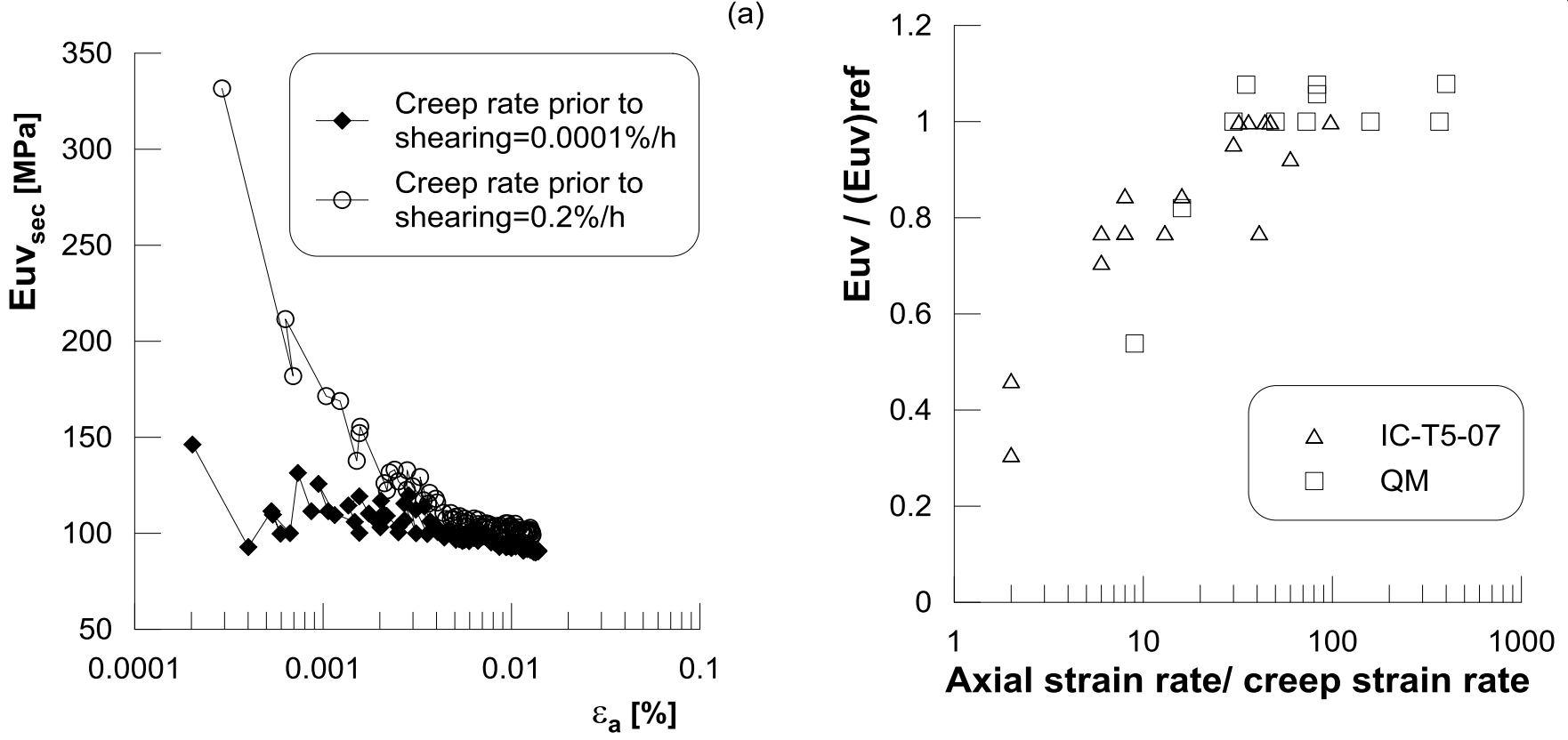

Figure 7: (a) Dependence of undrained secant vertical stiffness on preceding creep strain rate, (b) Dependence of normalised undrained vertical stiffness on the ratio of axial strain rate to creep strain rate

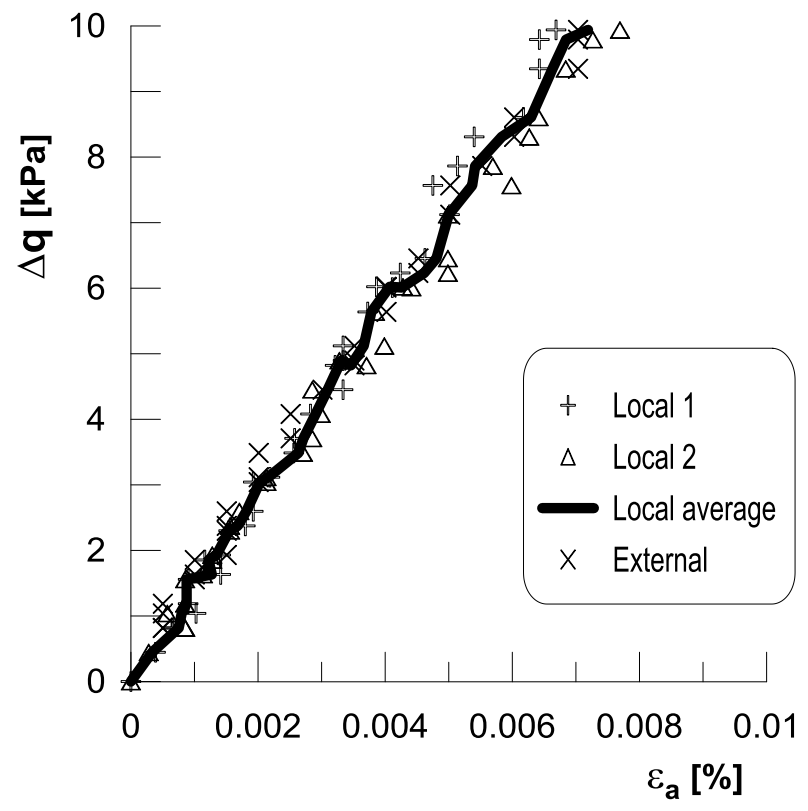

(a)

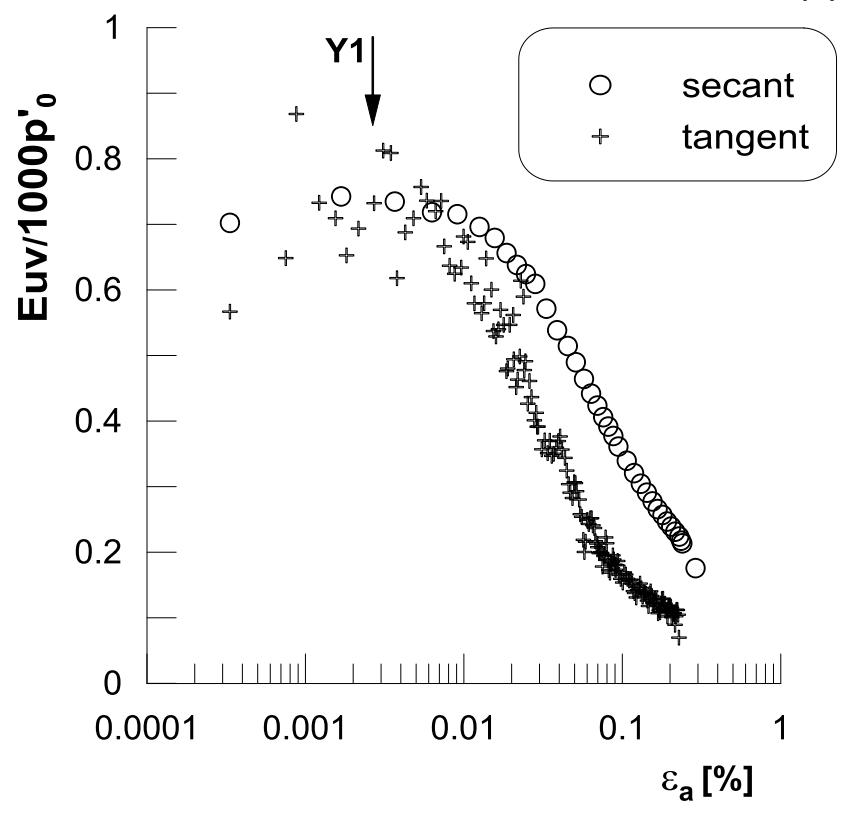

Figure 8: Undrained triaxial compression of QM sample from 8m below top of London Clay (a) stressstrain data, (b) decay curves of normalised undrained secant and tangent vertical stiffness 


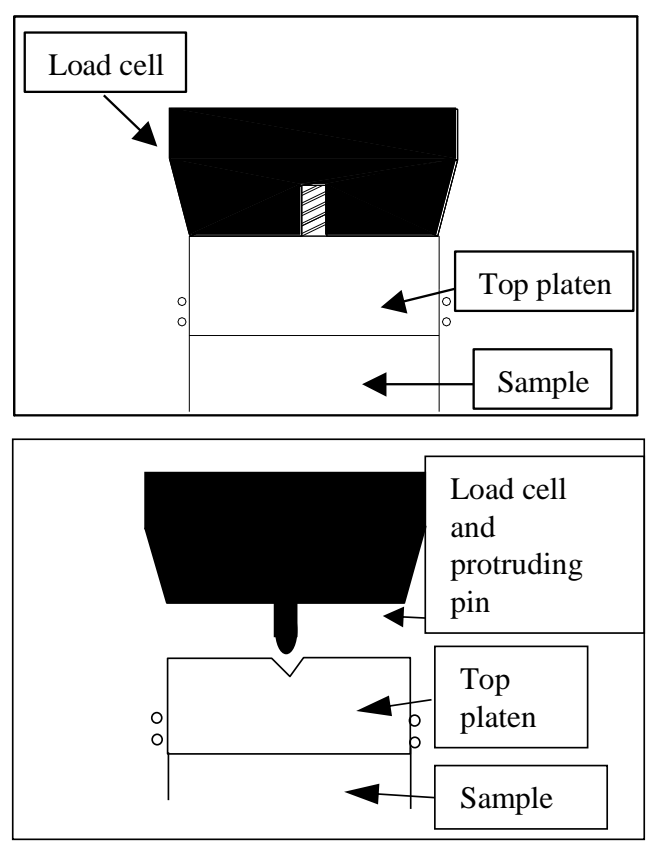

(a)

(b)

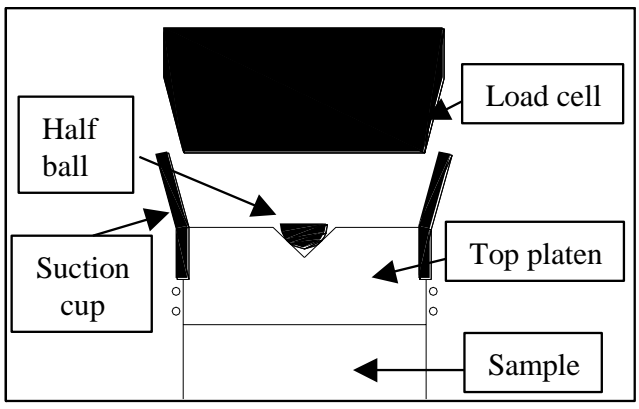

(c)

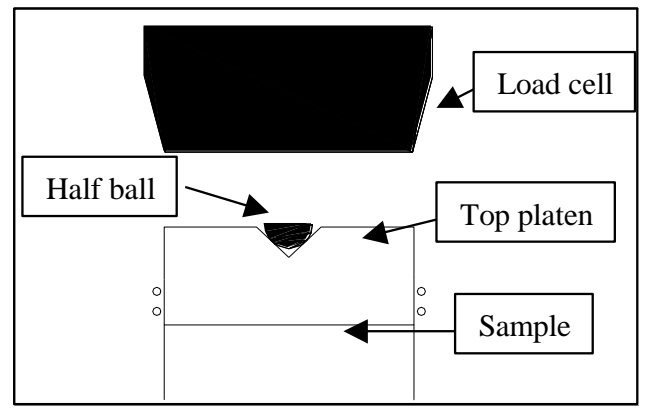

(d)

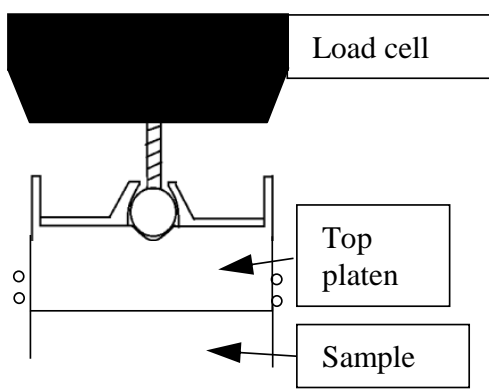

(e)

Figure 9: Load cell connections (a) rigid (b) pin (c) new suction cap for $100 \mathrm{~mm}$ diameter samples with half ball $(\mathrm{d})$ half ball only (e)fixed ball used in T5-00 
(a)

(b)
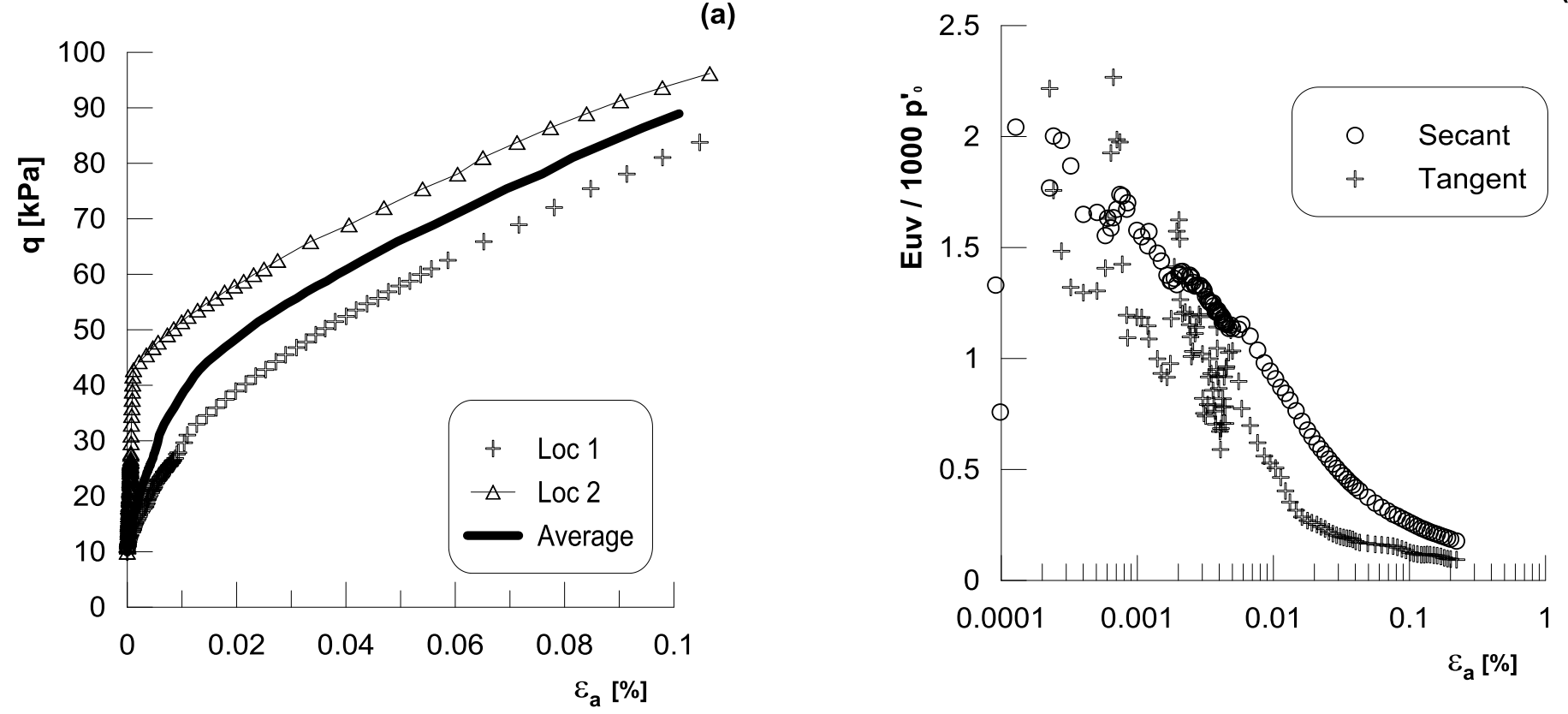

Figure 10: Undrained triaxial compression of IC-T5-07 sample from $32.5 \mathrm{~m}$ below the top of London Clay with a rigid connection between the load cell and the top platen (a) stress-strain data, (b) decay curve of normalised undrained secant and tangent vertical stiffness

(a)

(b)
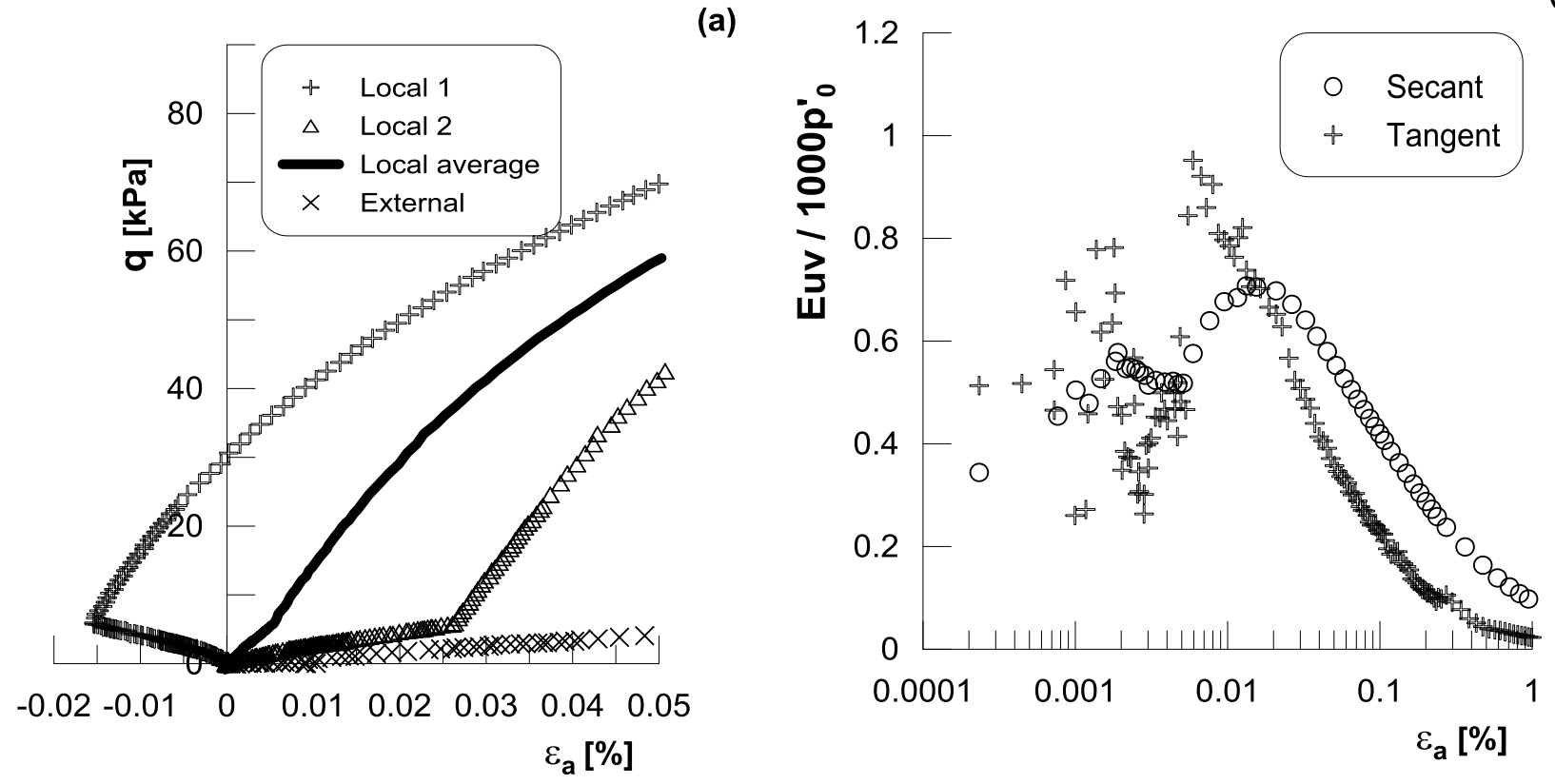

Figure 11: Undrained triaxial compression of IC-T5-07 sample from 21m depth, carried out using a half ball to apply the vertical load to the sample (a) stress-strain data, (b) decay curves of normalised undrained secant and tangent vertical stiffness 


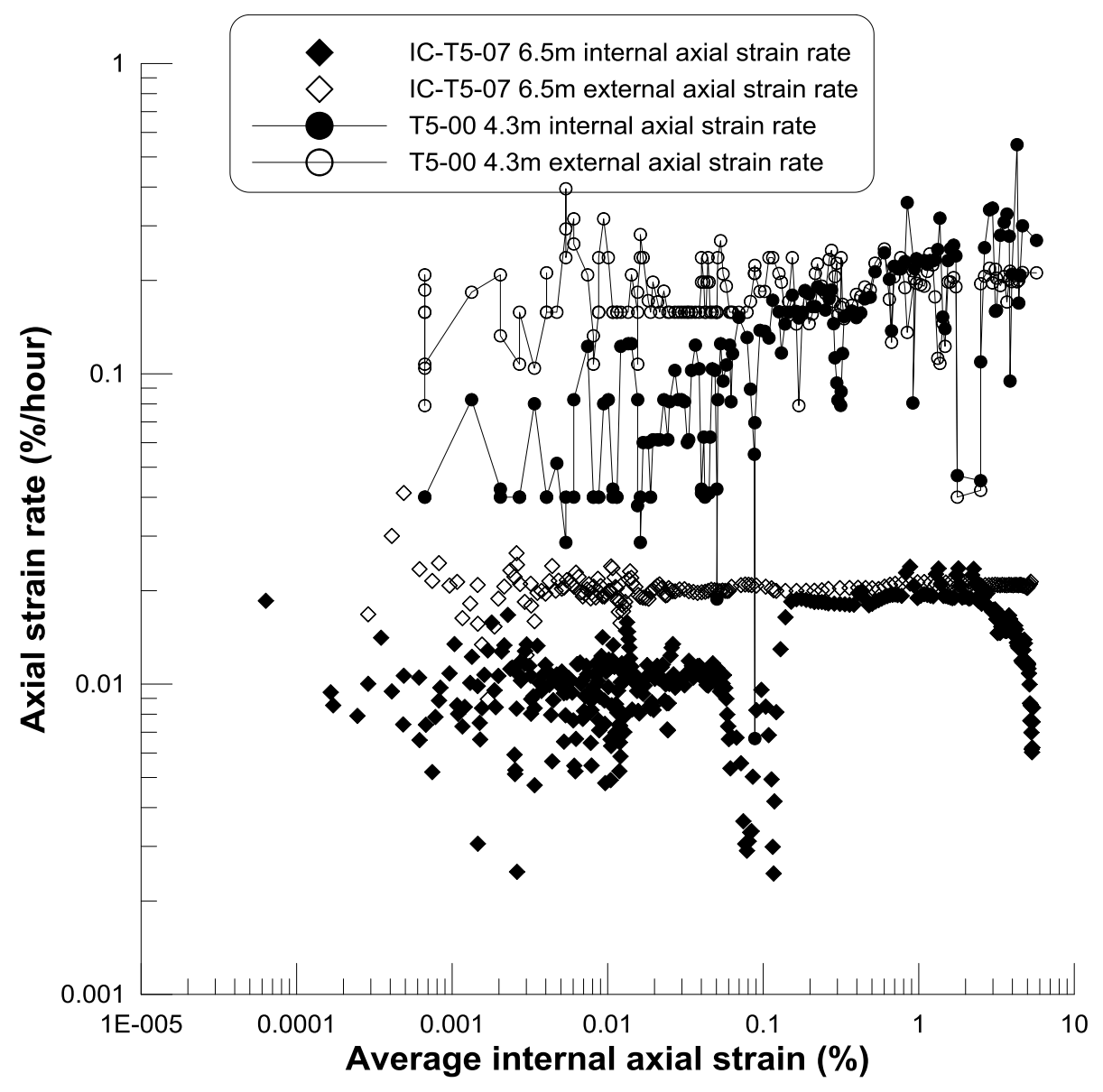

Figure 12: Comparison of internal and external strain rates in IC-T5-07 and T5-00 4.3m tests

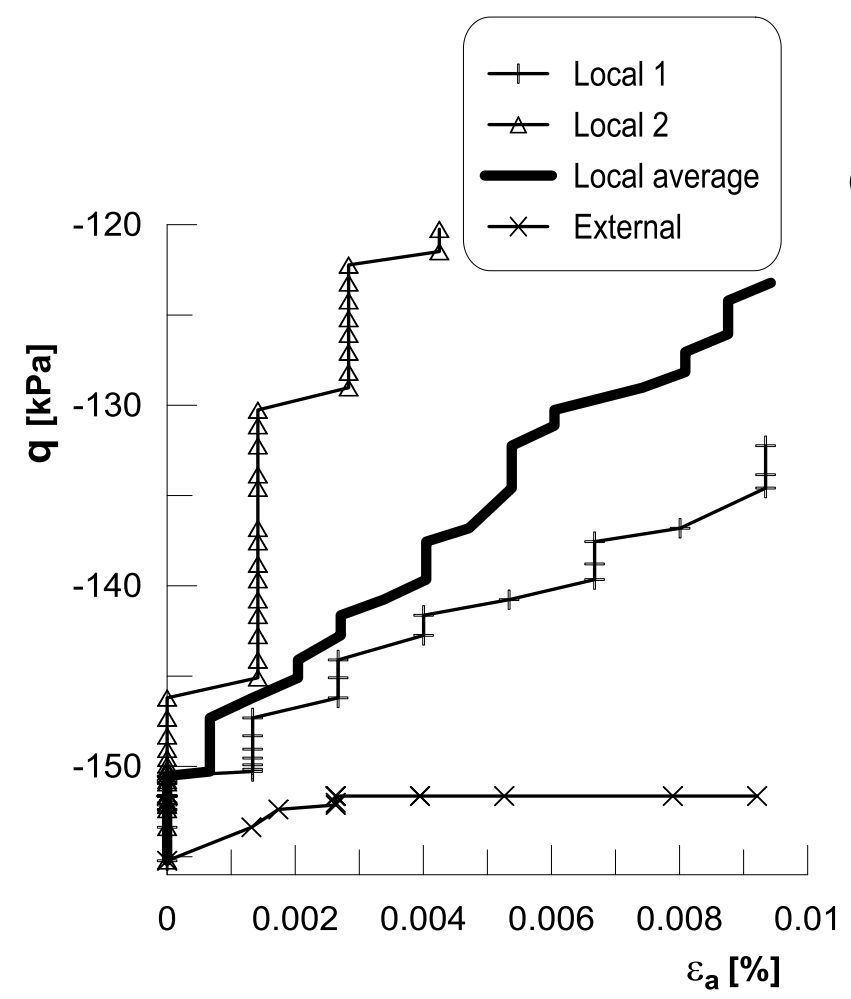

(a)

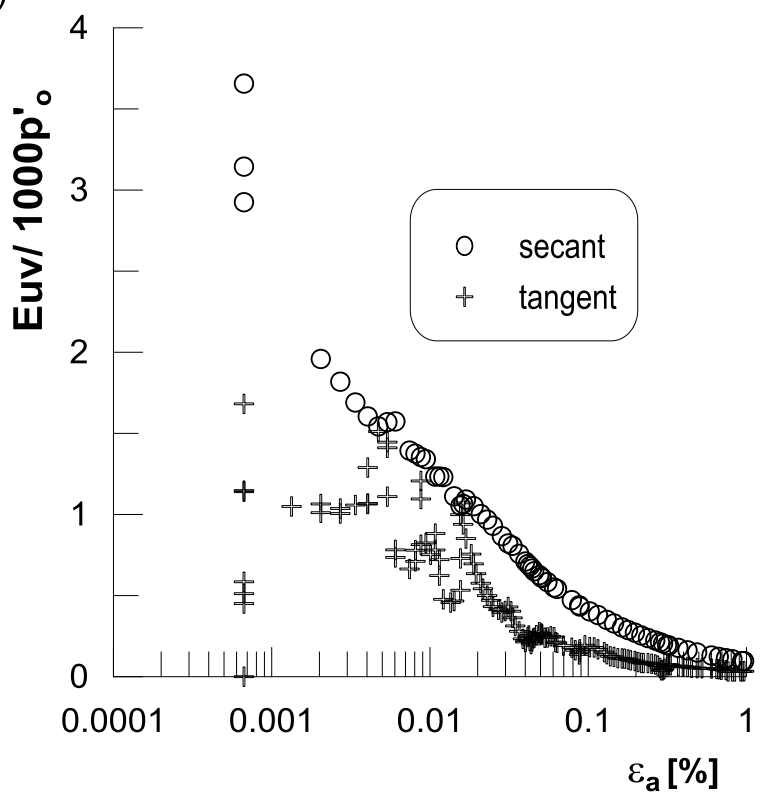

Figure 13: Undrained triaxial compression of T5-00 sample from 4.3m below the top of London Clay (a) stress-strain data, (b) decay curves of normalised undrained secant and tangent vertical stiffness 
(a)

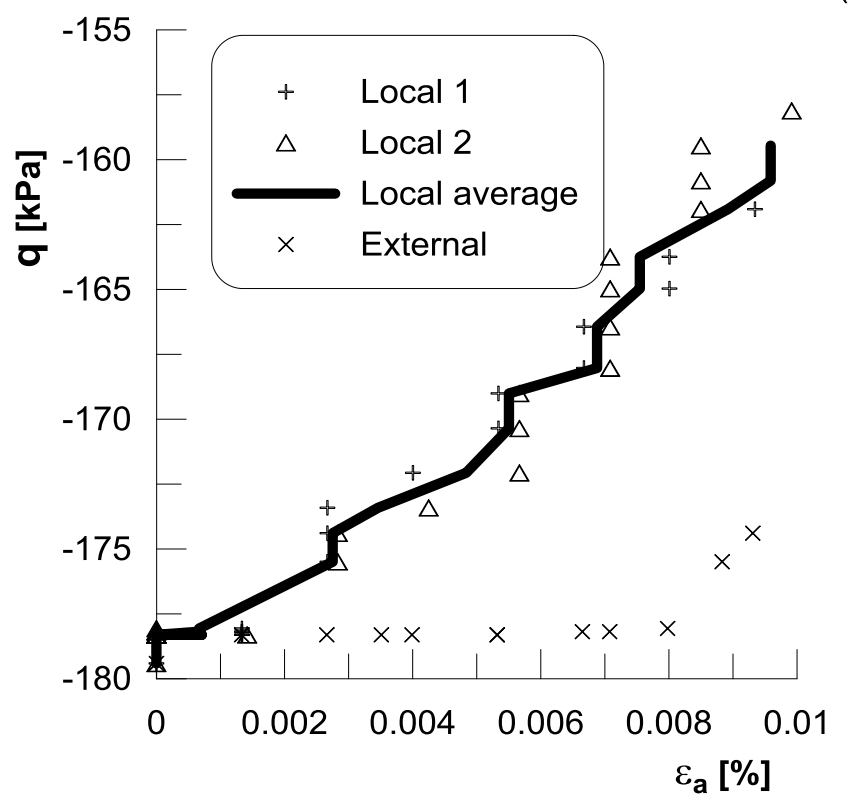

(b)

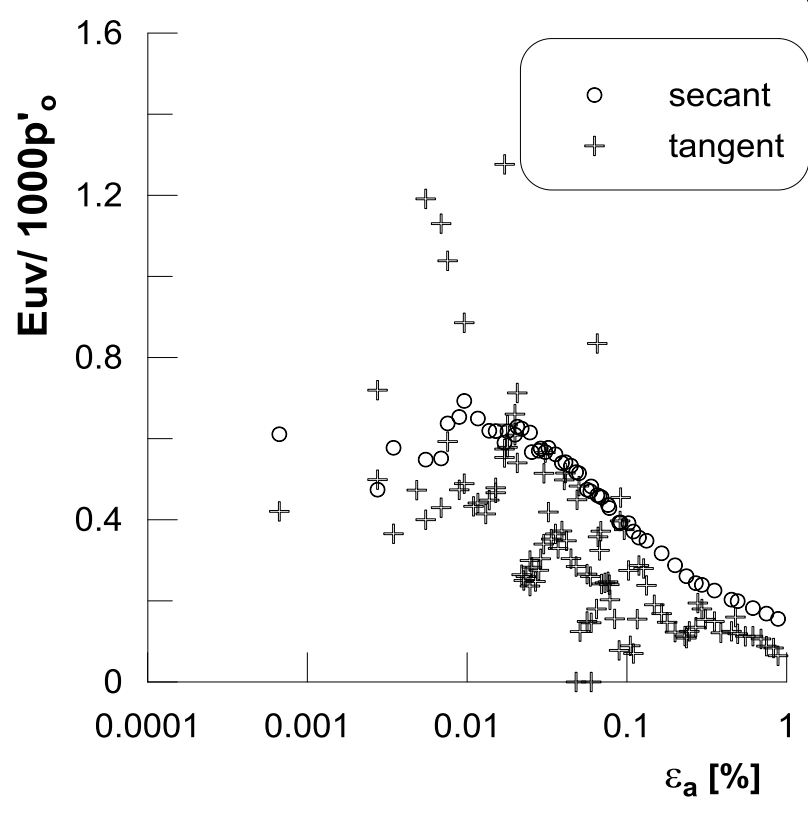

Figure 14: Undrained triaxial compression of T5-00 sample from $10.29 \mathrm{~m}$ below the top of London Clay (a) stress-strain data, (b) decay curves of normalised undrained secant and tangent vertical stiffness 